The selected area diffraction patterns (SAD) of the iron nanoparticles revealed the presence of bcc iron and a cubic spinel structure similar to $\gamma-\mathrm{Fe}_{2} \mathrm{O}_{3}$ and $\mathrm{Fe}_{3} \mathrm{O}_{4}$. Further examination with x-ray photoelectron spectroscopy showed that the oxidation state of iron was $\mathrm{Fe}^{3+}$, clearly identifying the oxide shell as $\gamma-\mathrm{Fe}_{2} \mathrm{O}_{3}$. With the use of convergent-beam electron diffraction, the scientists obtained single crystal electron diffraction patterns and identified the epitaxial relationship between the iron core and the oxide shell. When analyzing the thickness fringes observed in HRTEM images, the scientists estimated the thickness of the oxide layer as $4.2 \mathrm{~nm}$.

The investigators observed a continuous change in the orientation of adjacent iron $\{100\}$ and $\{110\}$ facets, and bending of the $\{111\}$ oxide fringes. As a result, they estimated a compressive strain of $3 \%$ due to the mismatch on the $\{100\}$ facets. They suggest that this compression reduced the oxide lattice spacing in the iron surface and therefore improved the passive characteristics of the oxide layer.

The analysis of the images obtained also showed that $\gamma-\mathrm{Fe}_{2} \mathrm{O}_{3}$ layers grew epitaxially on the iron surface. The researchers quantified the growth rate by using the Caberra-Mott theory of oxidation of metal. They report that the rate of oxidation is initially very fast but decreases considerably after the oxide shell is $3 \mathrm{~nm}$ thick, at room temperature conditions. For a 4-nm layer, the growth temperature is about $420 \mathrm{~K}$, which the researchers considered consistent with their experimental estimations. Following the assumptions taken in the application of this theory, the researchers suggest that the small size of the particles contribute to the growth of an epitaxial layer.

SIARI S. SOSA

\section{Silicon Analogue of Spiropentadiene is Isolated}

Disilenes, $\mathrm{Si}=\mathrm{Si}$ double bonded compounds, are commonly hard to isolate because they are unstable. As reported in the October 20 issue of Science, a group of researchers at Tohoku University, Japan, has synthesized and isolated a stable disilene, tetrakis[tri(tert-butyldimethylsilyl) silyl]spiropentasiladiene (compound 2), which is a silicon analogue of spiropentadiene (compound 1). As an original Si cluster $\left(\mathrm{Si}^{21}\right)$, compound 2 has very attractive features, according to the researchers. Electrons are delocalized over the whole cluster through spiroconjugation, which is very sensitive to the twisting of substituents at $\mathrm{Si}=\mathrm{Si}$ bonds. Therefore, the spiroconjugation can be tuned by the substituents. The researchers projected these features can be used for optoelectronic devices.

In their research, chemistry professor Mitsuo Kira and his colleagues established that the reaction of [tris(tert-butyldimethylsilyl)silyl]dibromochlorosilane with potassium graphite at $-78^{\circ} \mathrm{C}$ gives two products, one of which is compound 2. Crystallization from hexane gives compound 2, an oxygen- and moisturesensitive dark red crystal, in 3.5\% yield. Contrary to compound 1, which decomposes at $-100^{\circ} \mathrm{C}$, spiropentasiladiene does not evolve to decomposition/degradation before its melting point $\left(216^{\circ} \mathrm{C}-218^{\circ} \mathrm{C}\right)$. As previously proposed, the four bulky tri(t-butyldimethylsilyl)silyl groups contribute to the thermal stability of compound 2, but are not the main reason for the isolation. The fairly small strain energy of the ring systems in compound 2 is the key point for this successful isolation.

In studying the structure of compound 2 in comparison to other carbon and silicone compounds, Kira's group used ${ }^{1} \mathrm{H}$, ${ }^{13} \mathrm{C}$, and ${ }^{29} \mathrm{Si}$ nuclear magnetic resonance (NMR) spectroscopy; ultraviolet-visible spectroscopy; and x-ray crystallography. The spectroscopic data indicates significant interaction between two remote $\mathrm{Si}=\mathrm{Si}$ double bonds in the molecule. The $\mathrm{x}$-ray single-crystal analysis shows a substantial deviation from the perpendicular arrangement of the two rings in compound 2 . The two rings in compound 2 are a little twisted with a dihedral angle of $78.26^{\circ}$ and the two $\mathrm{Si}=\mathrm{Si}$ double bonds in these two rings are not planar. In contrast to tetrakis(di-tert-butylmethylsilyl) cyclotrisilene, which only has one three- membered ring, the length of $\mathrm{Si}=\mathrm{Si}$ double bonds and the Si-Si single bonds in compound 2 is longer and shorter, respectively.

The researchers are currently investigating the formation mechanism for compound 2. They said that the syntheses of various unknown types of group-14 organometallic compounds including silicon analogues of triple-bond molecules present new challenges in this field.

YING LI

\section{Transparent, Conductive Coatings Produced}

Researchers at the Fraunhofer Institute for Surface Engineering and Thin Films IST in Brunswick have developed a process to produce transparent, electrically conductive oxide coatings. They combined mid-frequency magnetron sputtering with a chemical reaction. The glass substrate is heated in a reactor and coated. In the course of magnetron sputtering, accelerated ions of inert gas "shoot" atoms out of a zinc-aluminum plate. The metal atoms are deposited on the substrate in a vacuum. For this coating to become both electrically conductive and transparent, the zinc needs to be oxidized so that the aluminum and zinc atoms bond together.

The researchers are pursuing this project in order to coat windshields to melt snow and ice. Bernd Szyszka of the IST said, "A prerequisite for use of these coatings systems is to convert the operating voltage for cars from 12 to 24 or even $42 \mathrm{~V}-$ a conversion that is expected over the next two to four years to improve the configuration of electronic systems in motor vehicles. Technically, the coatings can also function at low power, but manufacturing costs are then extremely high. With a higher voltage, thinner coatings suffice-which can be produced at substantially lower cost." The researchers at IST are currently using an industrial-scale plant to coat glass substrates of up to $0.6 \mathrm{~m}$ by $1 \mathrm{~m}$ in size.

Szyszka said that transparent and electrically conductive coatings are also needed for flat monitor screens and electrically switchable window panes for buildings. $\square$

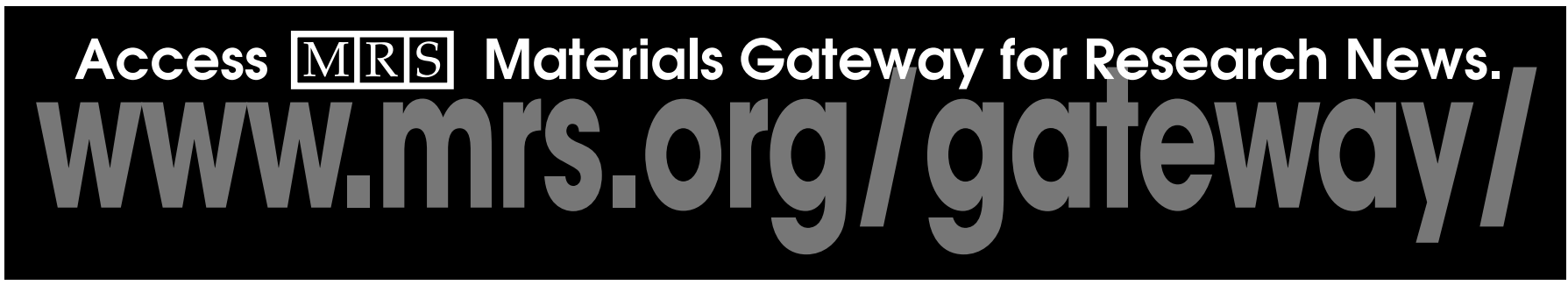

